\title{
Jimepamypa
}

1. Кіш Є. Б. Центральна Європа в сучасній системі єврорегіональної інтеграції : [монографія] / Єва Кіш. - Ужгород : Ліра, 2008. - 440 с.

2. Ткач Д. І. Сучасна Угорщина в контексті суспільних трансформацій: Монографія / Ін-т політ. і етнонац. дослідж. НАН України. - К. : МАУП, 2004. - 504 с.

3. Дж. Сакс, О. Півоварський. Економіка перехідного періоду // Уроки для України). Київ, «Основи»-1996. -159 с.

4. Kuczi Tibor. Kuczi, Tibor. Kisvállalkozás és társadalmi környezet / Small entrepreneurship and social environment). - Budapest: Replika, 2000.

5. Ласло Сюч, Ласло Соч. 2001 год в Венгрии: Движение вперед, но к чему? - Режим доступу : www/gallup.hu

6. Róna-Tas, Ákos Róna-Tas, Ákos. Economic Sociology in Europe: Hungary, Economic Sociology. European Electronic Newsletter (February 2002). -Vol. 3. - No. 2. - http://www.siswo. uva.nl/ES/esfeb02art4.html

7. Лучкина, Л. С. Социальные реформы в Содружестве Независимых Государств : науч. докл. / Л. С. Лучкина // Рос. акад. наук. Ин-т междунар. экон. и полит. исслед. - М. : ИМЭПИ PAH, 2002. $-95 \mathrm{c}$.

8. М. А. Усієвич. М. А. Усиевич. Десятилетие реформ в Венгрии. 90-е годы ХХ в. / «Новая и новейшая история». - 2002-09-01NNI-No. 005. - С. 86.

9. Ежегодный бюллетень жилищной и строительной статистики для Европы и северной Америки, 1998. - Нью-Йорк, Женева, ООН. - 1998. - С. 79.

10. Временные руководящие принципы по статистике распределения доходов, потребления и накопления домашних хозяйств // ООН, Нью-Йорк. - 1977. (Перепечатано в Экспресс-информации № 4 серии: Обследование бюджетов семьи и методы исчисления, М., 1990, Госкомстат СССР и НИИ статистики).

11. Nelson M. Tilly Ch., Walker I. Transforming Post-Communist Political Economies. - Washington, DC., National Academy Press. - p. 249.

12. Д. Ткач. Адаптація населення Угорщини до життя на мікрорівні в умовах глобалізації, 2002 / Діалог цивілізацій: Нові принципи організації світу : матеріали другої всесвітньої конференції. - К. : МАУП - С. 116-128.

13. Статистичний щорічник України за 2000 рік. - Київ, Техніка. - 2001. - С. 378.

14. Roggemann C. H., Scholz O., Tomann H. Welfare States in Transition: East and West. / Macmillan Press LTD, 1999. - p. 964 Ibid., p. 93.

15. Magyar statisztikai evkonyv. - 2000, Budapest.

УдК 330.15

Л.А. Баластрик

кандидат эконолических наук; доцент, кафедра эконолической теории, макро- и ликроэконолики Киевский университет ил. Тараса Шевченко

О.Г. Чумаченко кандидат эконолических. наук, доцент, кафедра национальной эконолики и финансов Университет эконолики и права «КРОК»

\section{Хозяйственный механизм природопользования}

Совершенствование методов экологизачии экономики осуществляется не только путем применения природосберегающих технологий и формирования экологических 
ограничений, но и вследствие создания и совершенствования хозяйственного механизма управления природоохранной деятельностью. В статье акиентировано внимание на макро- и микр уровнях решения проблем природопользования, рассмотрены основные составляющие хозяйственного механизмы природопользования.

Ключевые термины: хозяйственный механизм природопользования; организационно-правовой механизм природопользования; финансово-экономический механизм природопользования, поведенческий механизм природопользования.

Л О. Баластрик

кандида. еконолічни. наук; доцент, кафедра економічної теорії, макро- і мікроекономіки Київский університет ім. Тараса Шевченка

О Г. Чумаченко кандида. економічних наук, доцент, кафедра національної еконоліки та фінансів Університет еконоліки та права «КРОК»

\section{Господарський механізм природокористування}

Удосконалення методів екологізачії економіки здійснюється не тільки шляхом застосування природозберігаючих технологій та визначення екологічних обмежень, але i внаслідок створення і удосконалення господарського механізму управління природоохоронною діяльністю. В статті зосереджено увагу на макро- $і$ макрорівніх вирішення проблем природокористування; розглянуто основні складові господарського механізму природокористування.

Ключові терміни: господарський механізм природокористування; організаційноправовий механізм природокористування; фінансово-економічний механізм природокористування, поведінковий механізм природокористування.

\section{L.O. Balastryk \\ PhD in Economics, Associate Professor \\ Department of Economic Theory, Macro- and Microeconomics Taras Shevchenko National University of Kyiv \\ O.H. Chumachenko \\ PhD in Economics, Associate Professor Department of National Economy and Finance "KROK” University}

\section{Economic mechanism of the nature management}

Improving the methods of ecologizing of the economy is carried out not only by using the environmentally friendly technologies and the formation of environmental restrictions, but also by creating and improving of the economic mechanism for managing environmental activities. The article focuses its'attention on macro- and microlevels of solving the problems of nature management, the main components of the economic mechanisms of nature management are considered.

Keywords: economic mechanism of nature management; organizational and legal mechanism of nature management; financial and economic mechanism of nature management, behavioral mechanism of nature management. 


\section{Постановка проблемы}

Роль экологии и охраны природы приобретает в настоящее время все большую остроту и значение. Современные масштабы и способы использования природных богатств таковы, что человечество, черпая одни ресурсы, одновременно, притом нередко, безвозвратно губит другие, нарушает естественное равновесие и приводит природу в такое состояние, что она теряет основное свое свойство самовозобновления и уже не может восполнять нанесенный нами ущерб.

Экономика природопользования и охраны окружающей среды изучает экономическую сторону взаимодействия общества и природы. При этом, окружающая природная среда включает не только естественную среду, но и природную среду, весьма существенно преобразованную человеком. в том числе, урбанизированные, искусственно созданные ландшафты. Быстрое изменение технологий в сторону их неестественности (как производство синтетических вещей, которые сами не могут разложиться естественным образом; так, и чрезмерное потребление) приводят к ускоренному исчерпанию невозобновляемых природных ресурсов и нарастанию разрушительных процессов во всех экосистемах. Сегодня ряд регионов находятся в пограничной ситуации, когда отдельные компоненты биосферы начинают утрачивать способность к самовосстановлению. На этом фоне первостепенное значение приобретает анализ соответствия развития каждой страны в отдельности, и человечества в целом, критериям сохранения биосферы.

\section{Нерешенные ранее части общей проблемы}

Усовершенствование хозяйственного механизма природопользования требует пристального внимания не только потому, что касается всех членов общества во всех странах мира, но и выступает как ключевая задача современного общественного воспроизводства. Ограниченность ресурсов, загрязнение окружающей среды, повышение энергоэффективности нельзя рассматривать отдельно друг от друга. Их надо синтезировать в общий концептуальный «узел» и включать в парадигму развития общества.

\section{Формулирование целей статьи}

Целью данной статьи есть попытка сформировать методологию подхода к решению проблем экологического характера в системе общественного воспроизводства, разделить комплекс проблем мега-, макро- и микроуровня, имеющих межрегиональное, межгосударственное и глобальное измерение; а также создание хозяйственного механизма, который бы органически объединял финансовоэкономические, организационно-правовые и культурно-воспитательные формы и методы управления природоохранной деятельности.

\section{Изложения основного материала исследования}

Современная биосфера Земли - продукт развития приблизительно 2,2 2,5 миллиардов лет. Но лишь 200-300 мл. лет назад она обрела свое сегодняшнее состояние. В результате сложилась биосфера, включающая растения, почвенный покров, азотно-кислородную атмосферу и озоновый шар, животных и микроорганизмы. Основными ее создателями были потоки энергии солнца и зеленые фотосинтезирующие растения, способные связать данную энергию в растительную биомассу. Особую роль при этом сыграла почва, ставшая экологической нишей живого вещества и продуктом его жизнедеятельности.

Поскольку на протяжении жизни всех предыдущих поколений, человека больше всего интересовала продуктивность животных и растений, а не их разнообразие, то многие биоценозы на Земле существенно уменьшились. 10000 лет 
назад леса составляли 50-60\% суши, 100 лет назад - 30-40\%, а сейчас - 20-30\%. Это привело к снижению влагообмена, а значит, к росту пустынь. Если брать сельское и домашнее хозяйство, то достаточно красноречивыми будут следующие цифры: в середине XIX века суммарная биомасса человека и домашних животных составляла 5\% от биомассы наземных животных, уже к середине XX столетия она удвоилась и достигла $10 \%$, а в настоящее время превышает $20 \%$. Аналогичные тенденции наблюдаются и в области промышленного производства. Сейчас, на одного землянина в среднем за год добывается и выращивается примерно 20 тонн сырья (только из недр Земли ежегодно извлекается 50 куб. км ископаемых пород, что составляет свыше 100 млр. тонн), которые с использованием энергетической мощности в 2500 Вт и 800 тонн воды преобразуются в 2 тонны конечного продукта [4]. Многие из них являются опасными для человека и животного мира. Результатом такого влияния становится не только кризисное состояние окружающей среды и рост заболеваемости населения, но и необоснованные экономические, экологические и социальные затраты. С высокой вероятностью можно прогнозировать, что силовое соперничество и усиление конкуренции в борьбе за ресурсы будет сопровождаться усилением анархии и депрессии во многих странах периферии (к которым, к сожалению, относится Украина).

Формируя методологию подхода к решению проблем экологического характера в системе общественного воспроизводства, необходимо изучить и разделить комплекс проблем мега-, макро- и микроуровня, имеющих межрегиональное, межгосударственное и глобальное измерение.

На мегауровне главные задачи состоят в следующем:

- в экономической оценке последствий трансграничного загрязнения среды и ее учете в межгосударственных договорах и соглашениях;

- в учете экологических факторов и ограничений в системе международных финансовых отношений и торговле, а также в политике межгосударственной интеграции;

- в выработке и обосновании согласованной политики охраны окружающей среды на межгосударственном уровне с учетом императивов устойчивого развития.

Главными задачами макроуровня являются:

- поэтапная реализация в рамках национальной экономики концепции устойчивого развития;

- разработка и обоснование национальной экологической политики и механизма экологического регулирования с учетом фактора социальной справедливости;

- государственное регулирование конфликтных экологических интересов, когда, в силу рационального поведения, у главного потребителя нет мотивов к долгосрочному сохранению ресурсов, а у общества, напроти, - есть. В данном случае столкновение интересов неизбежны. Например, то, что выгодно лесозаготовительным компаниям, вредит местным жителям. В целом же страдает вся страна, теряются восстанавливаемые лесные ресурсы и биологическое разнообразие. Часто интересы основной части общества испытывают противодействие со стороны элиты. Опять же в силу ее рационального экономического поведения. Если, к тому же, элита способна оградить себя от последствий своих решений - она будет действовать в своих интересах, несмотря на то, что это негативно скажется на всех остальных.

Само по себе ужесточение экологического законодательства не решает проблем: в развитых странах. Быстро появляется «серый» бизнес, помогающий крупным предприятиям избавится от опасных отходов запрещенными способа- 
ми, а в странах «третьего мира» львиная доля производственной деятельности ведется на полулегальных мелких заводах, проконтролировать которые сложно.

На микроуровне должно акцентироваться внимание на разрешении следующих основных задач, среди которых:

- оценка и сопоставление затрат и результатов в природоохранной сфере; обоснование критериев и показателей эффективности природоохранных предприятий;

- установка пороговых значений нормы энергоэффективности для предприятий (bench-marking). Идея в том, чтобы не ограничиваться жалобами на собственников крупных промышленных объектов, которые не хотят инвестировать свои прибыли в модернизацию производства, а выдвигать им конкретные требования и применять ощутимые санкции за их несоблюдение;

- повышение энергоэффективности жилищно-коммунального хозяйства (ЖКХ). Финансирование государством ремонта жилищ, которые в результате должны уменьшить потребление энергии. Что же касается новых зданий, то они должны строиться уже с применением энергосберегающих технологий;

- обоснование принятия решений в отношении использования ограниченных ресурсов природы, как специфических общественных благ.

Более подробно остановимся на проблеме ТБО (твердых бытовых отходов).

Проблема переполненности полигонов ТБО под названием «кризис свалок» приводит к потерям украинской экономики в бытовых отходах 3,3 млр. тонн макулатуры, 660 тыс. тонн стекла, по 550 тыс. тонн черных металлов и текстиля, 25 тыс. тонн цветных металлов, которые Украина импортирует. При этом, рециклингу (переработке или вторичному использование) подвергаются примерно 5-8\% твердых отходов (в европейских странах аналогичный показатель составляет более $65 \%$ ). Только $2 \%$ поступает в утилизацию на экологически безопасные полигоны из захоронения отходов или мусоросжигательные заводоы. Стоит подчеркнуть, что, например, в Германии переработке подвергаются все отходы, в стране нет полигонов для захоронения ТБО. По подсчетам координаторов проекта «Зробимо Україну чистою!», рециклинг бытовых отходов может приносить достаточно высокий экономический эффект, ведь тонна «вторичной» бумаги стоит 300 грн., а металла - 1200-1250 гр. [8].

Сегодня ситуация с переработкой ТБО в Украине плачевная. Все экономические выгоды от рециклинга теряются, поскольку 97\% всего бытового мусора в смешанном виде попадают на полигоны. При этом, потенциальный доход рынка переработки мусора оценивается экспертами в 1 млр. грн. Этого уровня доходов можно достичь, включив в тарифы на вывоз мусора стоимость его переработки. Сегодня средний тариф на вывоз твердых отходов для населения составляет 35 грн. за м. куб. Если поднять тариф до 50-100 грн - сфера переработки мусора станет очень привлекательной для инвесторов. Для реализации этого необходимо: во-первых, организовать вывоз мусора и его четкую пофракционную сортировку. Во-вторых, нарастить мощности рециклинга отходов. По оценкам ученых, для комплексного решения проблемы и реализации первоочередных мероприятий, среди которых закрытие перегруженных полигонов и таких, которые не отвечают нормам экологической безопасности, Для покупка контейнеров и мусоровозов для обеспечения раздельного сбора фракций ТБО во всех населенных пунктах необходимо приблизительно 160 млрд грн [7].

На этом перечень проблем, связанных с охраной окружающей среды не исчерпываются. Роль экологии и природоохранных стандартов в современном обществе двоякая. Во-первых, это формирование ограничений при принятии хозяйственных решений. В свою очередь, Эти ограничения связаны с соблюдением приро- 
доохранного законодательства и вытекающим из него экологическим нормированием. Во-вторых, необходимо оптимизировать рыночные и административные инструменты согласования хозяйственной и природоохранной деятельности.

Первая группа предпосылок должна опираться на допустимый диапазон нормативов качества окружающей среды. Давно известны, как минимум, три внутренних норматива: предкризисная нагрузка на состояние окружающей среды; экономический оптимум нагрузки; социальный оптимум нагрузки. Социальный оптимум характеризуется потребностью общества в достижении санитарногигиенических или более жестких экологических нормативов. Выход на социальный оптимум возможен только на основе использования экологически чистых технологий, которые входят в состав шестого технологического уклада.

Финансовыми ресурсами перехода к социальному оптимуму служат как собственные средства предприятий, так и государственная финансовая поддержка. Предприятия должны иметь план достижения социальных нормативов качества окружающей среды, содержащий технологические и технические меры, сроки их осуществления и издержки по годам. Со стороны государства своевременно было бы внедрить льготы по кредитованию инвестиционных проектов, связанных со снижением нагрузки на окружающую среду, путем государственного субсидирования процентных ставок по кредитам. Другой стимулирующей мерой внедрения современных природоохранных технологий служит переход от существующей платы за загрязнение окружающей среды - к платежам на возмещение экономического ущерба от загрязнения.

В прогрессивных экономически развитых странах наблюдается рост значения стимулирующего воздействия экономических инструментов экологического регулирования экономики и предпринимательства. Именно они способствуют обеспечению соответствия между стоимостью продукции и природных ресурсов, когда возмещение расходов за причиненный ущерб окружающей среде осуществляется самим загрязнителем, а не всем обществом. Поэтому проблема усовершенствования хозяйственного механизма экономики природопользования является актуальной для всех стран и, особенно, для Украины.

Хозяйственный механизм природопользования - это совокупность финансовоэкономических, организационно-правовых и культурно-воспитательных форм и методов управления природоохранной деятельностью государства с целью сохранения природы, качества окружающей среды, рационального использования природных ресурсов, поддержки экологического равновесия и улучшения условий существования человечества. Структурными элементами хозяйственного механизма природопользования являются: финансово-экономический, организационно-экономический и поведенческий механизмы природопользования $[1,5]$.

Организационно правовой механизм природопользования - это система методов организации правового и административного регулирования процессов природопользования на основе научно обоснованного менеджмента, экономической оценки платы за право пользования природными ресурсами. А также возмещения потерь от нерационального использования, стимулирование безопасного для окружающей среды освоения и эксплуатации.

Под финансово-экономическим механизмом природопользования понимается совокупность, предусмотренных законодательством, экономических инструментов и методов обеспечения охраны окружающей среды и рационального природопользования на основе использования целевых финансовых ресурсов и фондов.

Поведенческий механизм природопользования включает систему учебно- 
воспитательных и информационных мер государства по переходу от «модели человека экономического» к «модели человека экологического».

Особенное место в современных условиях необходимо отвести именно поведенческому механизму природопользования. Повсеместное и широкое экологическое воспитание, а также образование, должно привести к изменению поведенческих механизмов общества. Информированность общества о пагубных последствиях стремительного роста материальных потребностей в век быстро меняющихся технологий, что приводит к углублению естественного экологического кризиса, сопровождающегося разрушением природной среды и деградацией биосферы - должна быть полной и своевременной. Но, еще более опасной, является социальная составляющая экологического кризиса, заключающаяся в неспособности государственных и общественных структур на всех уровнях, от национального до наднационального, остановить процесс деградации природы. И нельзя откладывать решения этих проблем до того времени, пока страна справится с экономическим кризисом. Ведь завтра уже будет поздно.

\section{Выводы}

1. Экологические проблемы влияют на экономику и образ жизни. Однако находиться множество поводов приуменьшить их важность. Озвучим некоторые из них: А. Экологические проблемы нужно компенсировать экономически. Это мнение предоставляет экологические интересы как роскошь, а их решение - в виде чистой денежной стоимости. Истина состоит в обратном. Экологические катастрофы обходятся намного дороже и в краткосрочной, и в долгосрочной перспективе. Их предотвращение экономит ресурсы государства, и населения. Б. Новые технологии решат старые проблемы. При этом подразумевается, что с завтрашнего дня начнут действовать технические новинки, которые будут работать преимущественно на решение экологических проблем, не создавая новых. Но, новая технология, не зависимо от того, решает ли она поставленную задачу, становится источником новых проблем. В. Если ресурс иссякнет, взамен можно найти другой. Разговоры о новых технологиях отвлекает от очевидной необходимости сейчас снизить интенсивность использования и потребления энергозатратных технологий и благ.

2. Экономическое благополучие определяется не только размером банковского счета и количеством потребляемых экономичных благ. Процветание, которым наслаждается «золотой миллиард», основано на растрате экологического капитала - невозобновляемых энергоресурсов, морских ресурсов, плодородной почвы, леса и т. д. Социально неправильно представлять эту растрату как зарабатывание денег и гордиться нынешним комфортом. Тем более, что история далекого и недалекого прошлого показывает, что общество может прийти к упадку всего за десять-двадцать лет после достижения пика рождаемости, роста экономики и государственной мощи. Причина проста: рекордно большое население и потребление ресурсов вызывают высокую нагрузку на окружающую среду, которая ведет к истощению ресурсов.Необходимо на государственном уровне решать проблему рециклинга. Утилизация, так называемого «мусора», должна быть превращена в сектор экономики: необходимо организовать централизованную систему сбора отходов; лицензировать переработку черных, цветных, драгоценных металлов и т. д.; создать льготы для переработчиков. Сложным остается вопрос, кто должен платить за утилизацию - потребители или производители с продавцами.

3. Усилить юридическую ответственность за правонарушения в области экологической безопасности. Действующее экологическое законодательство закрепляет перечень правонарушений в сфере экологической безопасности: наруше- 
ние прав граждан на экологически безопасную окружающую природную среду; нарушение норм экологической безопасности; нарушение экологических норм при проектировании, размещении, строительстве, реконструкции; введении в действие эксплуатации и ликвидации предприятий, сооружений, передвижных средств и других объектов; допущение сверхнормативных, аварийных залповых выбросов и сбросов загрязняющих веществ и других небезопасных влияний на окружающую природную среду; неприятие мероприятий относительно предупреждения и ликвидации экологических следствий аварий и другого вредного влияния на окружающую природную среду; нарушение природоохранных требований при хранении, транспортировке, использовании, обезвреживании и захоронении химических средств защиты растений, минеральных удобрений, токсических и радиоактивных веществ, производственных, бытовых и других видов отходов и др. [5]. Согласно с видами экологических правонарушений, в сфере обеспечения экологической безопасности виновные личности могут быть привлечены к дисциплинарной, административной, криминальной или гражданскоправовой ответственности. В реальной жизни в Украине присущий очень низкий уровень применения норм криминального права за нарушение природоохранного законодательства. Например, судимость за незаконную охоту в 2014 году составила $2,2 \%$; незаконное занятие рыбным, звериным или иным водным промыслом - 0,8\%; незаконная вырубка леса - 0,2\%; загрязнение моря - 0,002\%; загрязнение водных объектов - 0,2\% от всех преступлений.

4. И последняя, очень важная, на наш взгляд, составляющая возможности решения экологических проблем, которые стоят перед обществом. Это воспитание экологической культуры и информированности общества. Решение проблемы эколого-экономичного оптимума развития в будущем возможно, в том числе, и воспитанием сегодняшнего поколения.

\section{Jumepamypa}

1. Базилевич В. Д., Баластрик Л. О. Державні фінанси : навчальний посібник. - Вид. 2-ге, доп. - К. : Атіка, 2009. - 368 с.

2. Баластрик Л. А., Чумаченко О. Г. Экологические факторы общественного воспроизводства / Китайсько-українське гуманітарне співробітництво в рамках концепції «Один пояс - Один шлях» // Наукове видання. - КНР, Тяньцзинь, 2016/2017. - С. 98-108.

3. Баластрик Л. О., Чумаченко О. Г. Економічна безпека інвестиційної діяльності в умовах глобалізації : матеріали 4 міжнародної науково-практичної конференції [«Сучасні виклики розвитку світової економіки»]. - К. : Київський національний університет імені Тараса Шевченка, 2015. - С. 92-95.

4. Бобров А. Л., Палт М. В., Пахомова Н. В. «Энвайроментальная экономика, устойчивое развитие и управление природопользованием» / Вест. Моск. ун-та. - Сер. 6. Экономика. - 2011. - № 6. - C. 109- 117.

5. Грушко В. Г., Наконечна О. С., Чумаченко Р. Г. Національні фінанси : [підручник]. - К. : ВНЗ «Університет економіки та права «КРОК», 2017. - 660 с.

6. Закон Украины «Про охорону навколишнього природного середовища»

7. Україна поступово перетворюється в величезний смітник. - [Електронний ресурс]. - Режим доступу : http://24tv.ua/home/showSingleNews.do?pidsumki_tizhnya_ukrayina_ potstuvo. - Название с экрана

8. Чисте місто - система з комплексів переробки твердих побутових відходів [Електронний ресурс]. - Режим доступу : http:ukrproject.gov.ua/sites/default/files/pdf/chiste_misto4.pdf. - Название с экрана

9. Кузьмин А. «Батарейка убивает не хуже пули», 2000, 13.11.2013 [Електронний ресурс]. - Режим доступу : www.2000.ua/v-nomere/derzhava/.../batarejka-ubivaet-ne-khuzhepuli_arhiv_art.htm

10. Чумаченко О. Г. Первинне публічне розміщення акцій (IPO): теорія та практика вітчизняних компаній : [монографія] / В. І. Грушко, О. Г. Чумаченко-К. : ТОВ «Дорадо-Друк», 2009.-252 с. 